\title{
Surface Charge Switchable Supramolecular Nanocarriers for Nitric Oxide Synergistic Photodynamic Eradication of Biofilms
}

Dengfeng $\mathrm{Hu}^{\dagger}$, Yongyan Deng ${ }^{\dagger}$ Fan Jia, Qiao Jin*, and Jian Ji*

MOE Key Laboratory of Macromolecule Synthesis and Functionalization of Ministry of

Education, Department of Polymer Science and Engineering, Zhejiang University, Hangzhou, 310027, China.

E-mail: jinqiao@zju.edu.cn (Qiao Jin); jijian@zju.edu.cn (Jian Ji)

$\dagger$ The two authors contributed equally to this work.

* Corresponding authors.

\section{EXPERIMENTAL SECTION}

\section{Materials}

$\alpha$-cyclodextrin ( $\alpha$-CD), N-hydroxysuccinimide (NHS), 1-(3-dimethylaminopropyl)-3ethylcarbodiimide hydrochloride (EDC), 4-Nitrophenyl chloroformate (NC), Chlorin e6 (Ce6) and methoxypolyethylene glycol (PEG-OH, Mw=2000) were provided by Aladdin Reagent Co., Ltd. (Shanghai, China). N-Acetyl-D-penicillamine, 3-(4,5-dimethylthiazol-2-yl)-2,5diphenyl tetrazolium bromide (MTT) were purchased from Sigma-Aldrich. PEG macroinitiator 
PEG-Br was synthesized by the reaction of PEO-OH and 2-bromoisobutyryl bromide according to the procedure published by our group. All other reagents and solvents were of analytical grade and used as received without further purification.

\section{Characterizations}

The ${ }^{1} \mathrm{H}$ NMR spectra were recorded on a Bruker DMX500 spectrometer. The size and size distribution of the nanocarriers were measured by dynamic light scattering (DLS) measurements by Zetasizer Nano-ZS from Malvern Instruments equipped with a He-Ne laser $(633 \mathrm{~nm})$ at $25{ }^{\circ} \mathrm{C}$. The morphology of the nanocarriers was characterized by transmission electron microscopy (TEM) on a HT7700 TEM (Hitachi, Japan) at an accelerating voltage of $80 \mathrm{kV}$. The NO release was measured by TBR 4100 free radical analyzer with a NO sensing electrode (ISO-NOPF2000-CXXX) from World Precision Instruments, Inc. UV-vis spectra were recorded on a Shimadzu UV-2550 UV-vis spectrometer and the absorption was recorded from 200 to $900 \mathrm{~nm}$. Fluorescence measurements were made on a PTI QM-40 fluorescence spectrometer with the excitation wavelength at $488 \mathrm{~nm}$ (the slit width was $10 \mathrm{~nm}$ ) and the emission spectra from $500 \mathrm{~nm}$ to $600 \mathrm{~nm}$. Fluorescence images were observed by using a fluorescence microscope (Olympus IX81). Flow cytometry analysis of cell uptake was analyzed by a BD FACS-Calibur ${ }^{\mathrm{TM}}$ flow cytometer.

\section{Synthesis of $\alpha$-CD-Ce6 Molecule}

As shown in Scheme S1a, $\alpha$-CD-Ce6 was synthesized via a multistep synthetic route. $\alpha$-CD was activated with $\mathrm{NC}$ to obtain $\alpha$-CD-NC. Briefly, $5.00 \mathrm{~g} \alpha$-CD dissolved in $50 \mathrm{~mL}$ dry dimethyl formamide was activated with $6.23 \mathrm{~g} \mathrm{NC}$ in the presence of $4.27 \mathrm{~mL}$ triethylamine 
(TEA) under nitrogen atmosphere. The resulting mixture was stirred at $25^{\circ} \mathrm{C}$ for $24 \mathrm{~h}$ and then filtered to obtain clear solution. The product was purified by precipitating in methanol for three times and dried in vacuum at $35^{\circ} \mathrm{C}$ overnight. Secondly, for the synthesis of $\alpha$-CD-NH $2,0.9$ $\mathrm{mL}$ triethylenetetramine was mixed with $10 \mathrm{~mL}$ dimethyl formamide followed by addition of 1.25 mL TEA. $0.70 \mathrm{~g} \alpha$-CD-NC dissolved in $10 \mathrm{~mL}$ dimethyl formamide was added into the triethylenetetramine solution dropwise. The mixture was stirred at $60{ }^{\circ} \mathrm{C}$ for $48 \mathrm{~h}$ and the resultant solution was purified by precipitating three times in acetonitrile and dried in vacuum at $35{ }^{\circ} \mathrm{C}$ overnight. Lastly, to synthesize $\alpha$-CD-Ce 6 conjugate, $0.028 \mathrm{~g}$ Ce6 was dissolved in $10 \mathrm{~mL}$ DMSO and activated using $0.025 \mathrm{~g}$ EDC and $0.016 \mathrm{~g}$ NHS. After $2 \mathrm{~h}, 0.03 \mathrm{~g} \alpha-\mathrm{CD}-\mathrm{NH}_{2}$ dissolved in $10 \mathrm{~mL}$ DMSO solution was added in the above solution slowly. The reaction was proceeded for another $12 \mathrm{~h}$ under nitrogen atmosphere and then the solution was exhaustively dialyzed against DMSO for $24 \mathrm{~h}$ (MWCO 1000) and distilled water for $48 \mathrm{~h}$, the $\alpha$-CD-Ce6 was obtained via lyophilization.

\section{Synthesis of $\alpha$-CD-NO Molecule}

$\alpha-C D-N O$ was synthesized via a multistep synthetic route as shown in Scheme S1b. Firstly, $3.0 \mathrm{~g} \mathrm{~N}$-acetyl-D-penicillamine was dissolved in $10 \mathrm{~mL}$ pyridine and kept at $0{ }^{\circ} \mathrm{C}$ for $30 \mathrm{~min}$. $3.97 \mathrm{~mL}$ acetic anhydride was added in the flask dropwise under nitrogen atmosphere and stirred for $24 \mathrm{~h}$ at $0^{\circ} \mathrm{C}$. The redundant solvents were then removed by evaporation at reduced pressure until only an orange liquid remained. The raw product was dissolved in chloroform and washed with $1 \mathrm{M}$ hydrochloric acid three times. The chloroform phase was collected and dried with magnesium sulfate. The solid was filtered and the obtained solution was evaporated to remove the solvent. The product was dried in vacuum to obtain N-Acetyl-D-penicillamine 
thiolactone (NAP-thiolactone). Secondly, $0.035 \mathrm{~g} \mathrm{NAP-thiolactone} \mathrm{and} 0.20 \mathrm{~g} \alpha$-CD-NH were dissolved in $8 \mathrm{~mL}$ DMF and stirred for $24 \mathrm{~h}$. The mixture was precipitated in acetonitrile and dried in vacuum to obtain $\alpha$-CD-SH. Lastly, $0.10 \mathrm{~g} \alpha$-CD-SH and $0.05 \mathrm{~mL}$ tert-butyl nitrite were dissolved in $5 \mathrm{~mL}$ DMF and stirred for $24 \mathrm{~h} . \alpha-\mathrm{CD}-\mathrm{NO}$ was collected by being precipitated in acetonitrile and dried in vacuum.

\section{Synthesis of PEG-(KLAKLAK) $)_{2}$-DA and PEG-(KLAKLAK) $)_{2}$-SA}

As shown in Scheme S1c, 10.0 mg PEG-(KLAKLAK) 2 was dissolved in HEPES buffer (pH 8.5) and kept at $0{ }^{\circ} \mathrm{C} .7 .0 \mathrm{mg}$ 2,3-dimethylmaleic anhydride (DA) was added in the solution and stirred for $24 \mathrm{~h}$. The mixture was purified by ultrafiltration to remove the unreacted DA and obtain PEG-(KLAKLAK) $)_{2}$-DA. The synthetic method of PEG-(KLAKLAK) ${ }_{2}$-SA was similar to the abovementioned procedure, except that the anhydride was succinic anhydride $(\mathrm{SA})$.

\section{Synthesis of Supramolecular $\alpha-C D-C e 6-N O-D A$}

The $\alpha$-CD-Ce6-NO-DA was prepared through the host-guest interaction between $\alpha$-CD and PEG. Typically, $2 \mathrm{~mL}$ DMSO with $8.0 \mathrm{mg} \alpha-\mathrm{CD}-\mathrm{Ce} 6,8.0 \mathrm{mg} \alpha-\mathrm{CD}-\mathrm{NO}$ and 4.0 mg PEG-bDA in a flask were stirred $4 \mathrm{~h}$ intensely. And then, deionized water was put slowly followed by $4 \mathrm{~h}$ stirring. Next, sonicate was used on the resulting solution for $20 \mathrm{~min}$ followed by exhaustively dialyzed (MWCO 3500) against water and stored at $4{ }^{\circ} \mathrm{C}$ prior to use. In addition, $\alpha$-CD-Ce6-NO-SA were formed in the same way. DLS and TEM was used to measure the size and morphology of the nanocarriers. At last, to determine Ce6 and NO loading content in the micelles, $1 \mathrm{~mL}$ micellar solution was lyophilized and then weighted. UV-vis spectrum was 
used to determine the concentrations.

\section{In Vitro GSH Measurement}

To investigate the GSH change, the GSH concentration was measured by GSH test kit (KeyGen KGT006). ${ }^{47} \alpha$-CD-Ce6-NO-DA and GSH were well mixed (0, 4:1, 2:1, 1:1 final concentration ratio of GSH and NO). Next, GSH test kit specifications was used to manage the mixed solutions. UV-vis spectrum was used to determine the GSH levels at $410 \mathrm{~nm}$. On the basis of the following Equation, GSH concentrations were calculated (A represented the absorbance and $\mathrm{C}$ stood for the concentration).

$\left.\mathrm{C}_{\mathrm{GSH}}=\left(\mathrm{A}_{\text {measured }}-\mathrm{A}_{\text {blank }}\right) /\left(\mathrm{A}_{\text {standard }}-\mathrm{A}_{\text {blank }}\right) * \mathrm{C}_{\mathrm{GSH} \text { standard }}\right)$

\section{In Vitro ROS Generation of $\alpha$-CD-Ce6-NO-DA}

The probe DCFH-DA (Beyotime S0033) was used to measure the generated ROS level with or without NO. According to a reported procedure, DCFH-DA was transformed to dichlorofluorescein. ${ }^{48}$ Then, $300 \mu \mathrm{L}$ of $\alpha$-CD-Ce6-NO-DA NPs solution $\left(20 \mu \mathrm{g} \mathrm{mL} \mathrm{m}^{-1} \mathrm{NO}\right.$ equivalent and $10 \mu \mathrm{g} \mathrm{mL}^{-1} \mathrm{Ce} 6$ equivalent) was mixed with $100 \mu \mathrm{L}$ dichlorofluorescein solution followed by $660 \mathrm{~nm}$ He-Ne laser exposure $\left(0.2 \mathrm{~W} \mathrm{~cm}^{-2}\right) . \alpha-\mathrm{CD}-\mathrm{Ce} 6 \mathrm{NPs}$ solution (10 $\mu \mathrm{g} \mathrm{mL} \mathrm{m}^{-1} \mathrm{Ce} 6$ equivalent) and PBS were also handled as the same process. Then, the changed fluorescence intensity was evaluated under $488 \mathrm{~nm}$ as excitation wavelength.

\section{Detection of Peroxynitrite Anions}

The probe dihydrorhodamine 123 (DHR) (Energy Chemical D1054) was applied to measure peroxynitrite anions $\left(\mathrm{ONOO}^{-}\right)$generation from $\alpha$-CD-Ce6-NO-DA nanocarriers. DHR and $\alpha-$ CD-Ce6-NO-DA nanocarriers were well mixed in $0.1 \mathrm{M}$ sodiumphosphate buffer $(\mathrm{pH}=7.4,3$ 
$\mathrm{mL}$ ) to prepared suspensions with the final concentration $0.1 \mathrm{mM}$ and $0.05 \mathrm{mM}$, respectively. Then, $660 \mathrm{~nm} \mathrm{He}-\mathrm{Ne}$ laser $\left(0.2 \mathrm{~W} \mathrm{~cm}^{-2}\right)$ was used to irradiate the suspensions for $1 \mathrm{~min}$ and UV-vis spectrum was used to analyzed the colored supernatant.

\section{GSH in Biofilm Measurement}

The GSH in biofilm was evaluated employing the GSH test kit. Typicaly, MRSA biofilm with a bacterial density of $1 \times 10^{9}$ cells per well was harvested by the above methods in 96 -well plates. Next, the biofilms were dealt with PBS, $\alpha$-CD-Ce6-DA, $\alpha$-CD-NO-DA, $\alpha$-CD-Ce6-NODA (20 $\mu \mathrm{g} \mathrm{mL}^{-1} \mathrm{NO}$ equivalent and $10 \mu \mathrm{g} \mathrm{mL} \mathrm{m}^{-1} \mathrm{Ce} 6$ equivalent), respectively. $2 \mathrm{~h}$ later, the solution on the biofilm was removed and then the biofilm was washed for three times with PBS. Subsequently, the biofilm was harvested ultrasonic processing for $10 \mathrm{~min}$. Then the GSH in biofilm was studied by UV-vis spectrum with evaluating $410 \mathrm{~nm}$ absorbance using GSH test kit. Finally, the GSH level was calculated by the formula in In vitro GSH measurement part.

\section{In Vitro Bactericidal Effect of Nanocarriers by Live/Dead Staining Assays}

At first, PBS or $\alpha$-CD-Ce6-SA (Ce6 $10 \mu \mathrm{g} \mathrm{mL}^{-1}$ ) or $\alpha$-CD-NO-SA (NO $20 \mu \mathrm{g} \mathrm{mL}^{-1}$ ) or $\alpha$ CD-Ce6-NO-SA (Ce6 $10 \mu \mathrm{g} \mathrm{mL} \mathrm{mL}^{-1}$ and NO $20 \mu \mathrm{g} \mathrm{mL}{ }^{-1}$ ) or $\alpha$-CD-Ce6-DA (Ce6 $10 \mu \mathrm{g} \mathrm{mL}{ }^{-1}$ ) or $\alpha$-CD-NO-DA (NO $20 \mu \mathrm{g} \mathrm{mL} \mathrm{m}^{-1}$ ) or $\alpha$-CD-Ce6-NO-DA (Ce6 $10 \mu \mathrm{g} \mathrm{mL} \mathrm{m}^{-1}$ and NO $20 \mu \mathrm{g}$ $\mathrm{mL}^{-1}$ ) were put into the MRSA biofilm in 96 well plates for incubation for $2 \mathrm{~h}$. And then the biofilm irradiated with laser $\left(660 \mathrm{~nm}, 0.2 \mathrm{~W} \mathrm{~cm}^{-2}\right)$ for $1 \mathrm{~min}$. After laser irradiation, biofilms in 96 well plates were incubated by BacLight Live/Dead dye for $15 \mathrm{~min}$ in dark. Then, sterile PBS was used to slightly wash off the redundant dye for three times. Finally, the fluorescence microscope was employed toobserve the biofilms in 96 well plates. 


\section{Combination Index (CI) Analysis}

Combination index $(\mathrm{CI})$ analysis provides qualitative information on the nature of drug interaction, and CI, a numerical value calculated as described in equation below, also provides a quantitative measure of the extent of drug interaction.

$$
\mathrm{CI}=\frac{\mathrm{Cce6,50}}{\mathrm{IC} 50, \mathrm{ce} 6}+\frac{\mathrm{CNO}, 50}{\mathrm{IC} 50, \mathrm{NO}}
$$

$\mathrm{C}_{\mathrm{ce} 6,50}$ and $\mathrm{C}_{\mathrm{NO}, 50}$ are the concentrations of $\mathrm{Ce} 6$ and $\mathrm{NO}$ used in combination to achieve $50 \%$ drug effect. $\mathrm{IC}_{50 \text {, ce6 }}$ and $\mathrm{IC}_{50, \text { NO}}$ are the concentrations for single agents to achieve the same effect. An CI of less than, equal to, and more than 1 indicates synergy, additivity, and antagonism, respectively.

\section{Cytotoxicity of Nanocarriers Measured by MTT Assays}

MTT assays was used to evaluate the cytotoxicity to healthy cells of different nanocarriers. Firstly, NIH 3T3 fibroblast cell was used to serve as model cell. These cells were seeded into 96 well plates with a density of 8000 cells per well in $180 \mu \mathrm{L}$ DMEM culturing medium each well for 24 hours culturing. Then PBS or $\alpha$-CD-Ce6-SA $\left(\mathrm{Ce} 610 \mu \mathrm{g} \mathrm{mL} \mathrm{m}^{-1}\right)$ or $\alpha$-CD-NO-SA (NO $20 \mu \mathrm{g} \mathrm{mL}{ }^{-1}$ ) or $\alpha$-CD-Ce6-NO-SA $\left(\mathrm{Ce} 610 \mu \mathrm{g} \mathrm{mL}-1\right.$ and NO $20 \mu \mathrm{g} \mathrm{mL}{ }^{-1}$ ) or $\alpha$-CD-Ce6DA $\left(\right.$ Ce6 $10 \mu \mathrm{g} \mathrm{mL}^{-1}$ ) or $\alpha$-CD-NO-DA (NO $20 \mu \mathrm{g} \mathrm{mL}{ }^{-1}$ ) or $\alpha$-CD-Ce6-NO-DA (Ce6 $10 \mu \mathrm{g}$ $\mathrm{mL}^{-1}$ and NO $20 \mu \mathrm{g} \mathrm{mL}^{-1}$ ) were put into the wells, respectively. Forty-eight hours later, MTT solution $\left(20 \mu \mathrm{L}, 0.1 \mathrm{mg} \mathrm{mL}^{-1}\right)$ was put into each well. After incubation for 4 hours, in order to dissolve the obtained crystals, the medium was wiped off and DMSO $(150 \mathrm{~mL})$ was put into each well. The microplate reader (MODEL 550, Bio Rad) was used to record the absorbance at $570 \mathrm{~nm}$. Moreover, the cytotoxicity of $\alpha$-CD-Ce6-SA (Ce6 $\left.20 \mu \mathrm{g} \mathrm{mL}^{-1}, 40 \mu \mathrm{g} \mathrm{mL}^{-1}\right), \alpha$-CD- 
NO-SA (NO $40 \mu \mathrm{g} \mathrm{mL} L^{-1}, 80 \mu \mathrm{g} \mathrm{mL} L^{-1}$ ), $\alpha$-CD-Ce6-NO-SA (Ce6 $20 \mu \mathrm{g} \mathrm{mL} \mathrm{mL}^{-1}$ and NO $40 \mu \mathrm{g}$ $\mathrm{mL}^{-1}, 40 \mu \mathrm{g} \mathrm{mL} \mathrm{m}^{-1}$ and NO $\left.80 \mu \mathrm{g} \mathrm{mL} \mathrm{m}^{-1}\right), \alpha$-CD-Ce6-DA $\left(\mathrm{Ce} 620 \mu \mathrm{g} \mathrm{mL}^{-1}, 40 \mu \mathrm{g} \mathrm{mL}{ }^{-1}\right), \alpha$-CDNO-DA (NO $40 \mu \mathrm{g} \mathrm{mL} \mathrm{m}^{-1}, 80 \mu \mathrm{g} \mathrm{mL}{ }^{-1}$ ) and $\alpha$-CD-Ce6-NO-DA (Ce6 $20 \mu \mathrm{g} \mathrm{mL}{ }^{-1}$ and NO 40 $\mu \mathrm{g} \mathrm{mL} L^{-1}, 40 \mu \mathrm{g} \mathrm{mL}^{-1}$ and NO $80 \mu \mathrm{g} \mathrm{mL}^{-1}$ ) was also investigated by the same methods. 
(a)
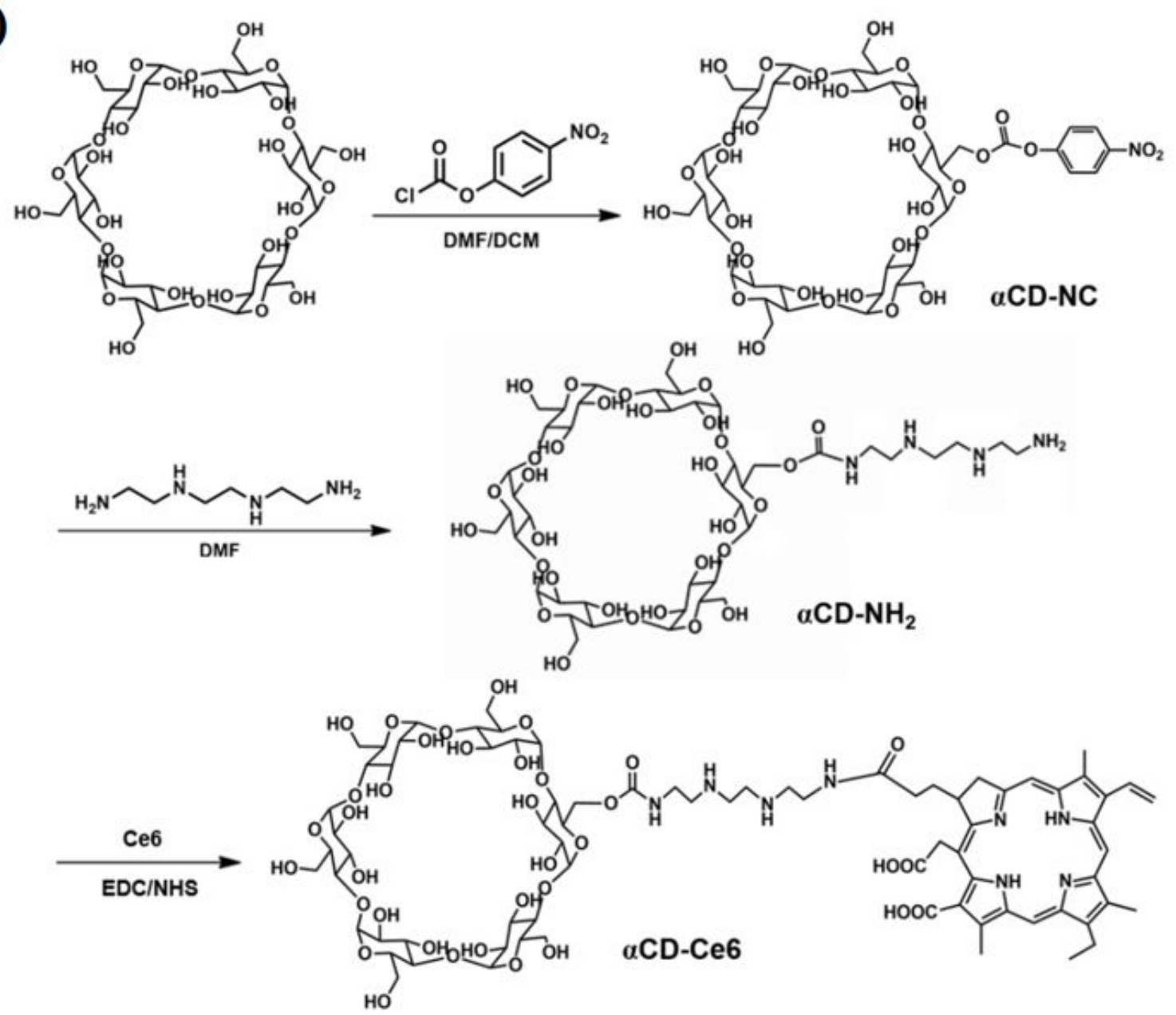

(b)

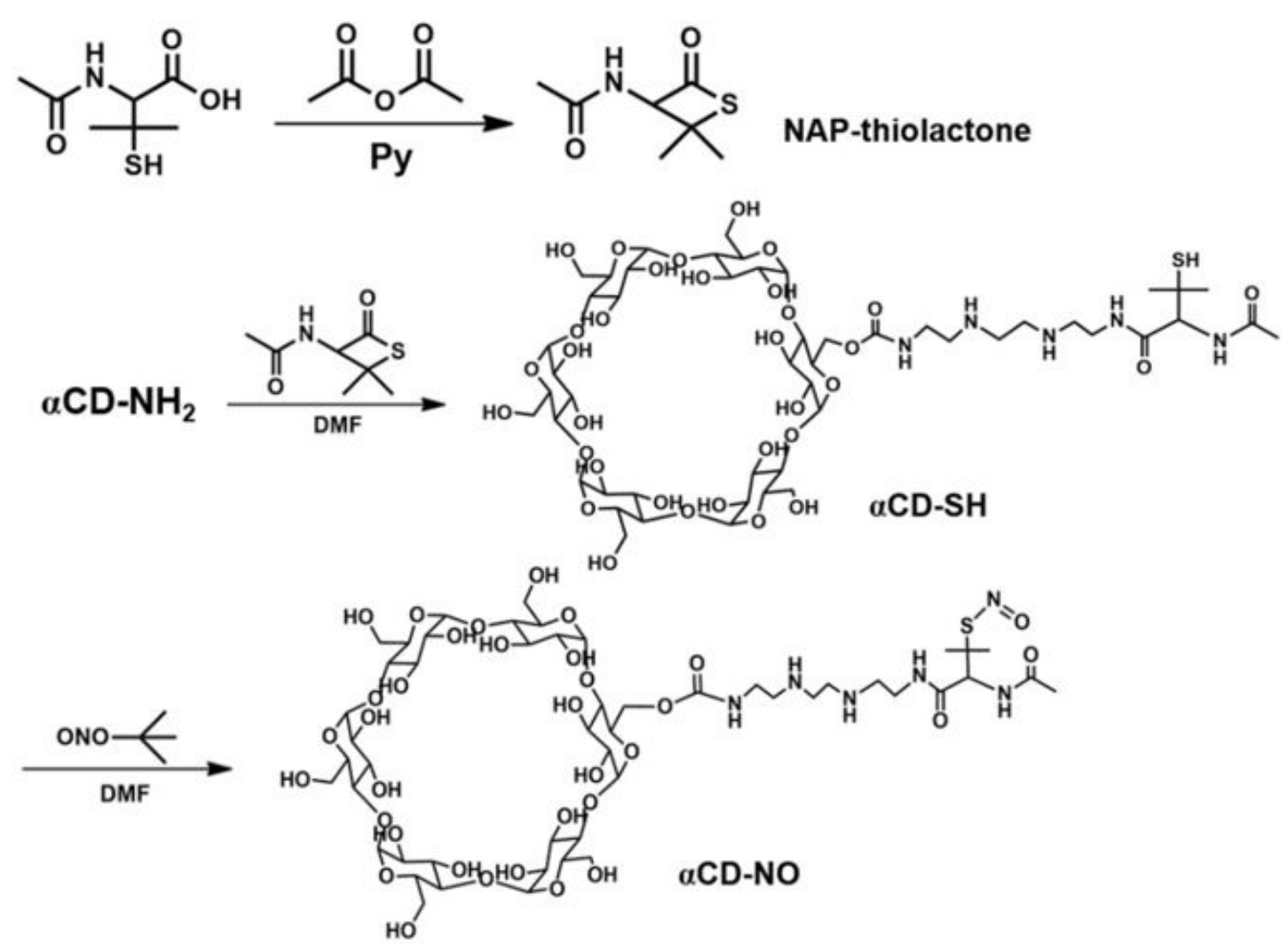


(c)

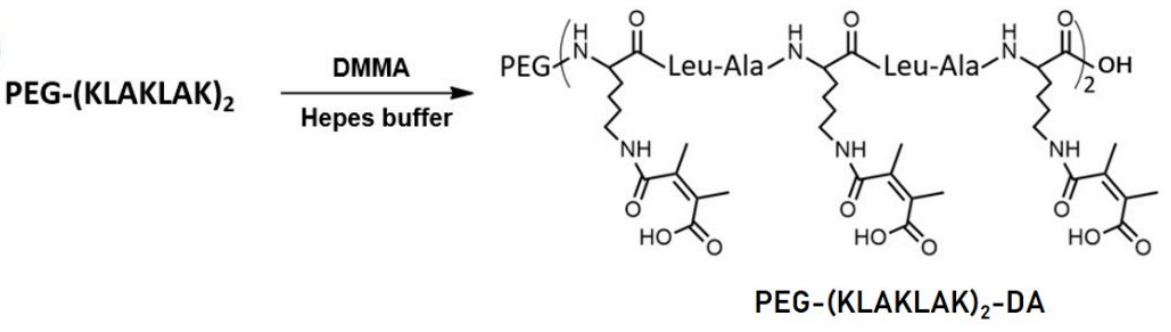

(d)

(e)

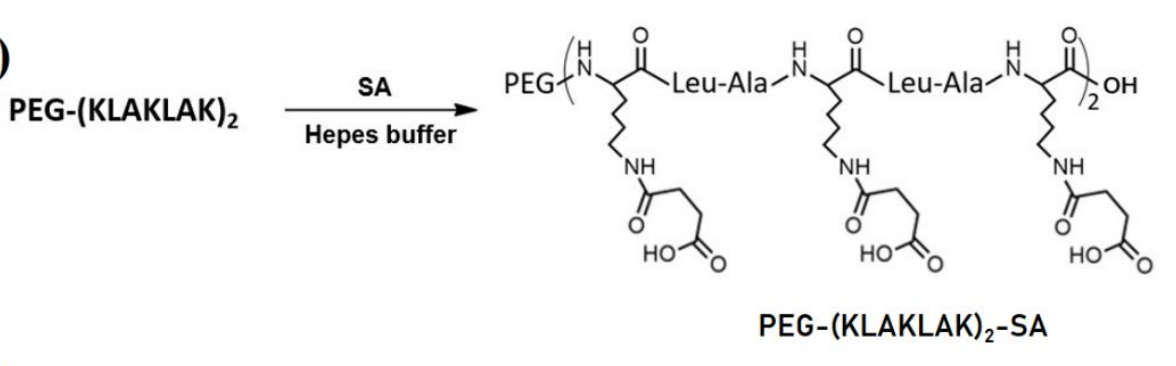

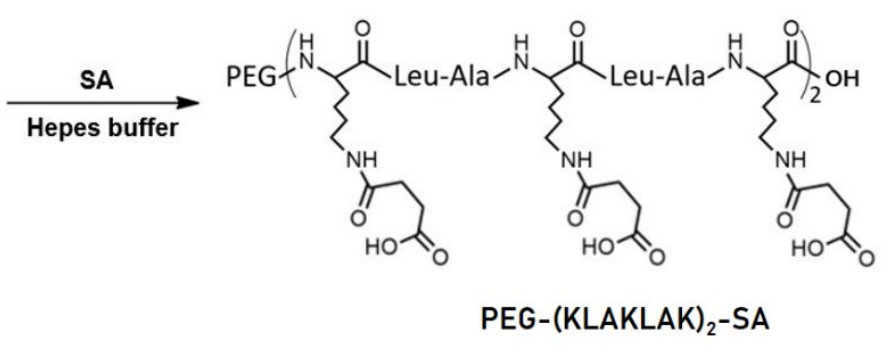

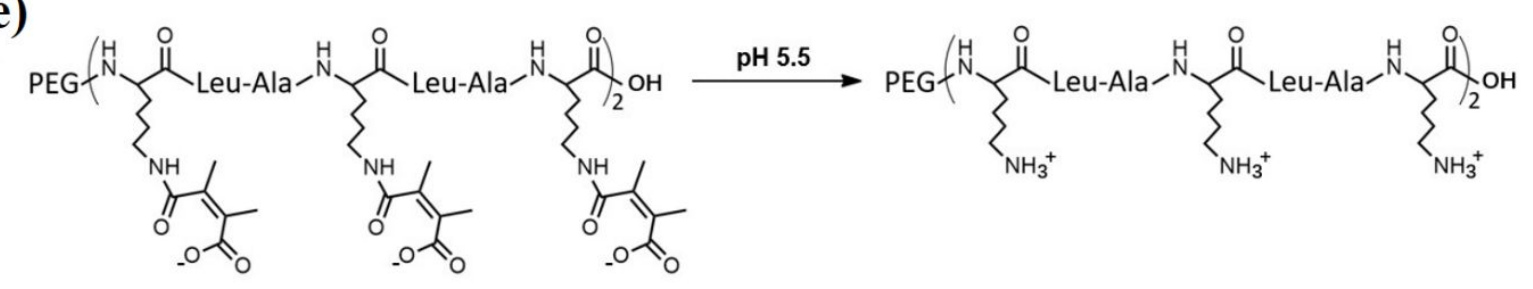

Scheme S1. Detailed synthetic routes of (a) $\alpha$-CD-Ce6, (b) $\alpha$-CD-NO, (c) PEG-(KLAKLAK) $)_{2}$

DA and (d) PEG-(KLAKLAK)2-SA; (e) Acid-activated charge reversal of PEG$(\text { KLAKLAK })_{2}$-DA at $\mathrm{pH} 5.5$. 
(a)

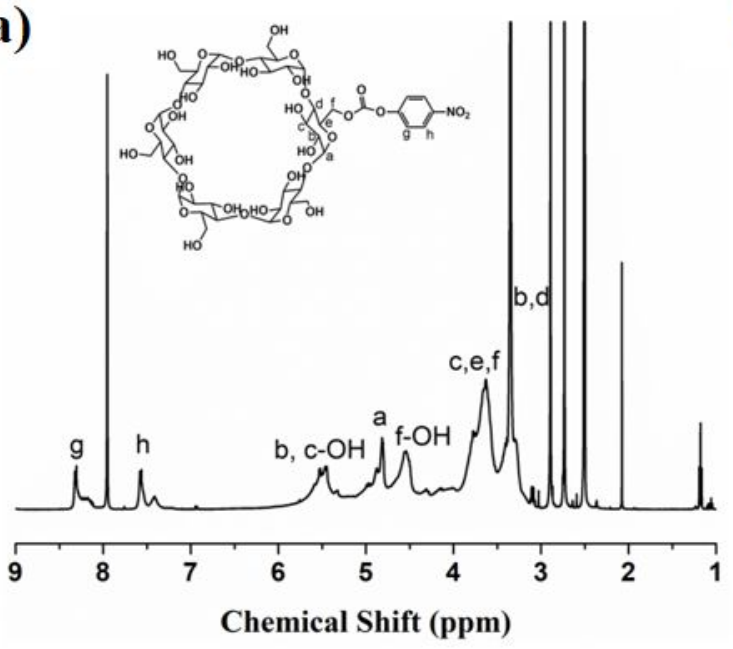

(c)

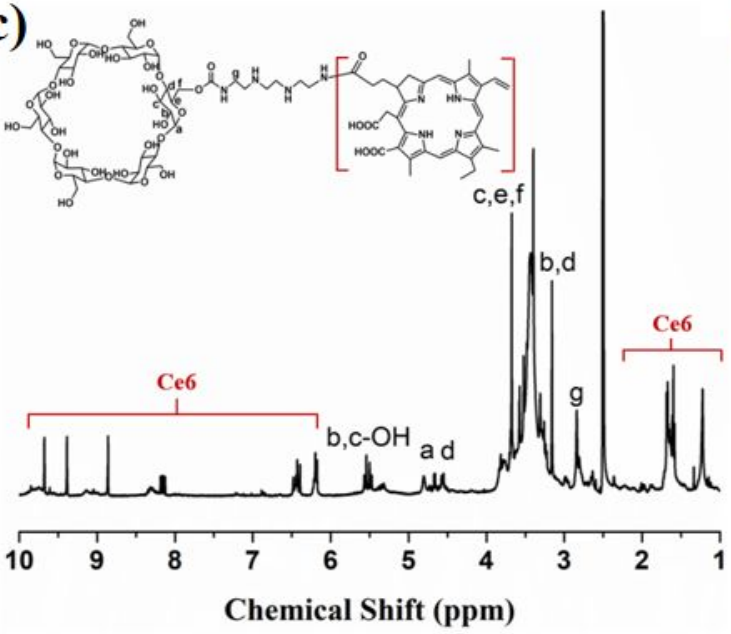

(e)

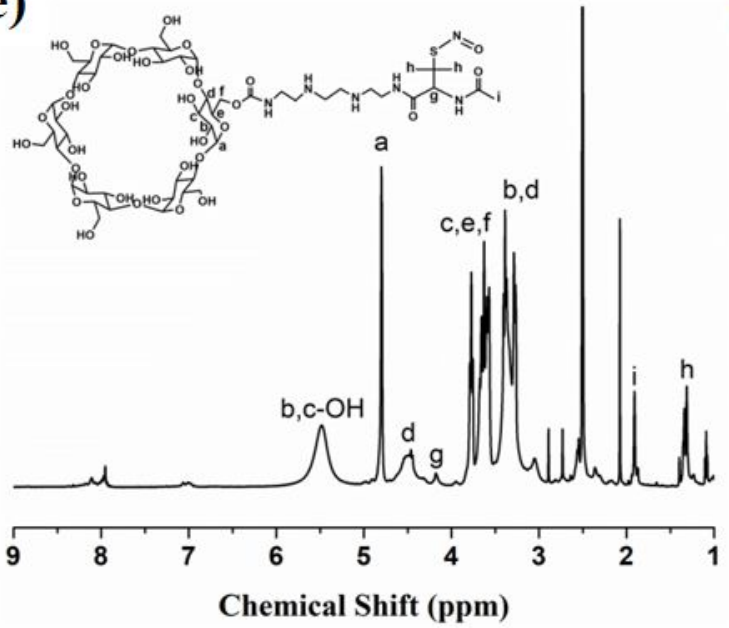

(b)

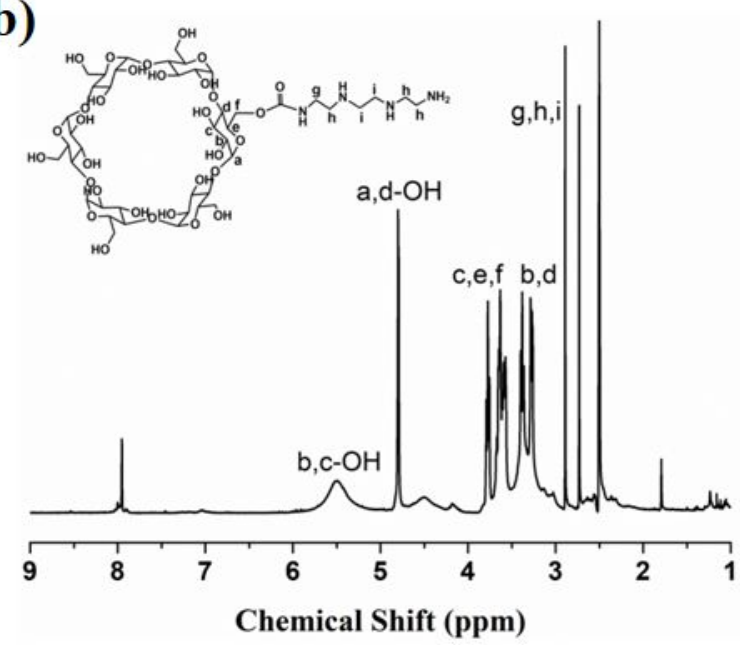

(d)

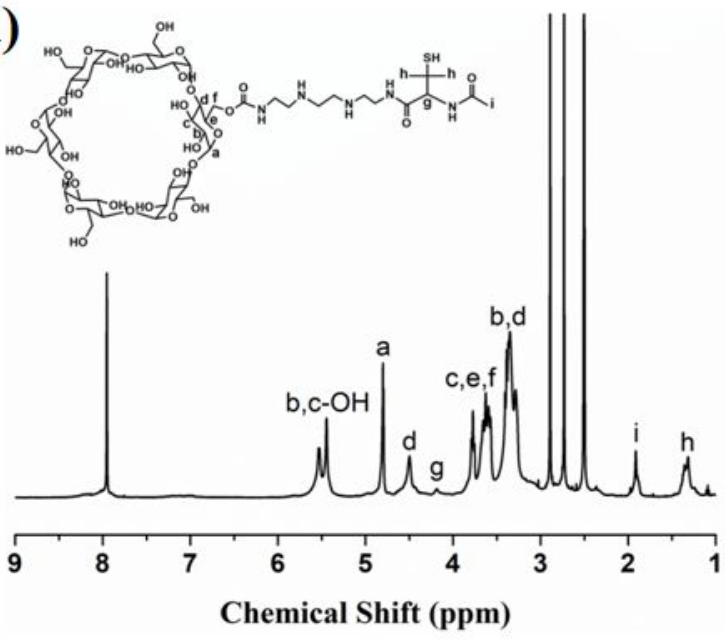

(f)

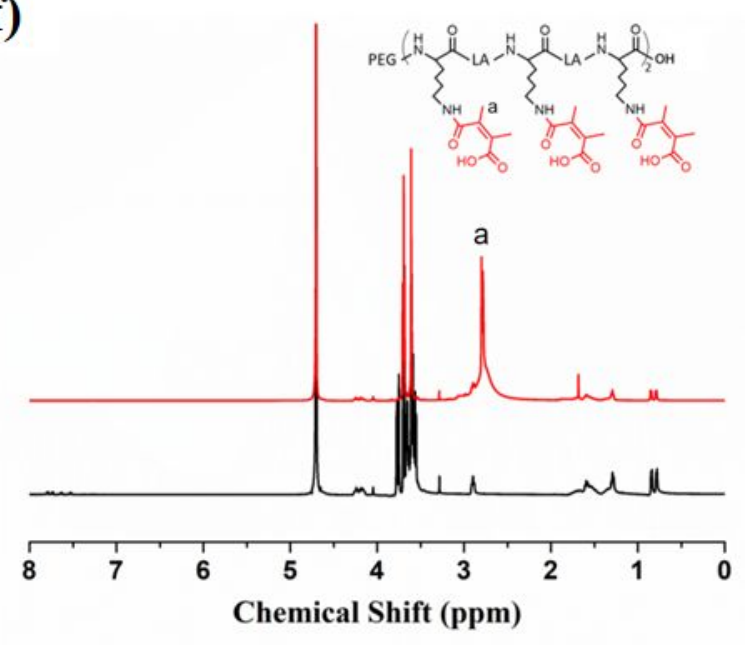

Figure S1. ${ }^{1} \mathrm{H}$ NMR spectra of (a) $\alpha-\mathrm{CD}-\mathrm{NC}$, (b) $\alpha-\mathrm{CD}-\mathrm{NH}_{2}$, (c) $\alpha-\mathrm{CD}-\mathrm{Ce} 6$, (d) $\alpha-\mathrm{CD}-\mathrm{SH}$, (e) $\alpha$-CD-NO, (f) PEG-(KLAKLAK) $)_{2}$-DA. 
(a)

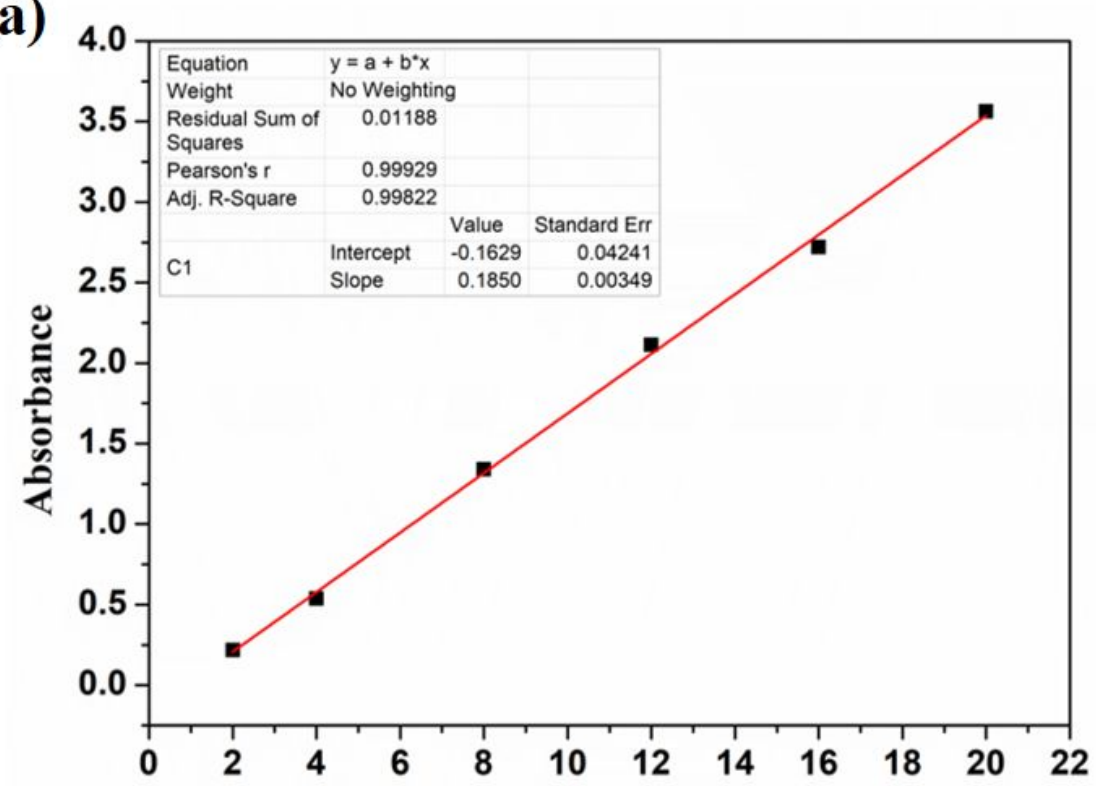

(b)

Ce6 concentration $\left(\mu \mathrm{g} \mathrm{mL}^{-1}\right)$

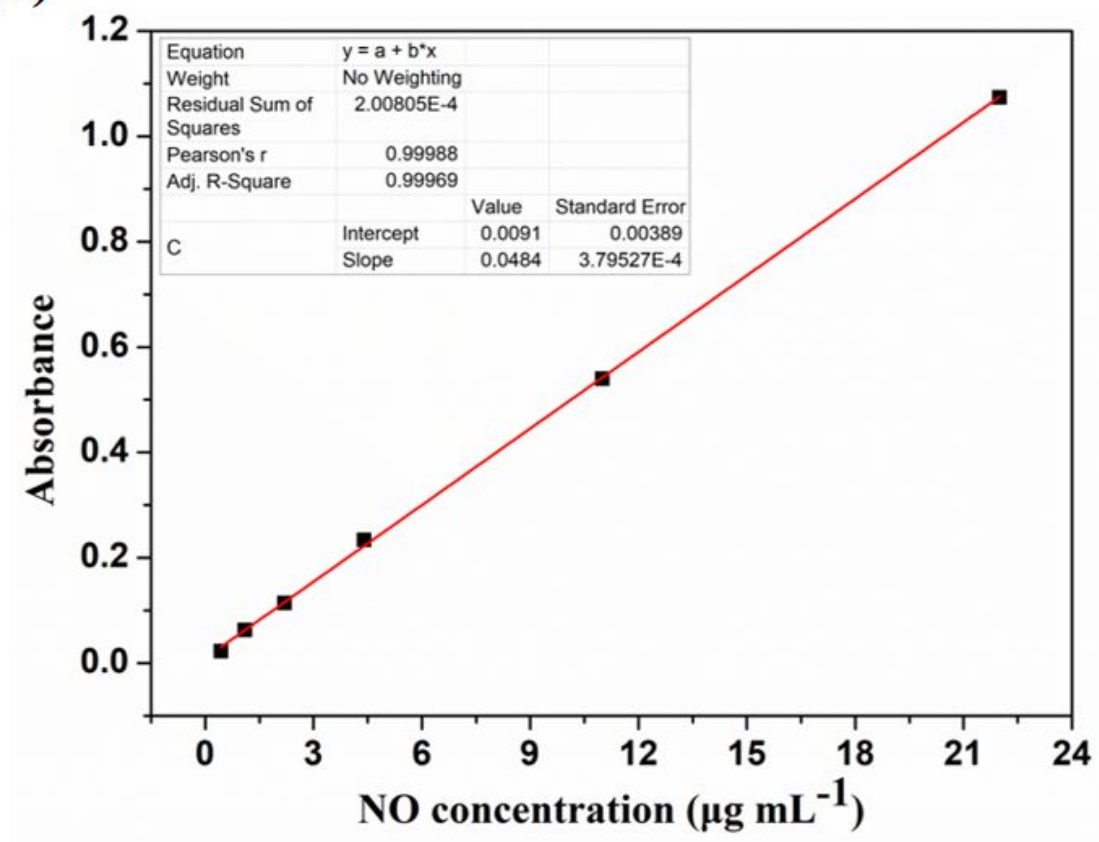

Figure S2. The calibration curve of (a) Ce6 and (b) NO by UV-vis spectrum. 
(a)

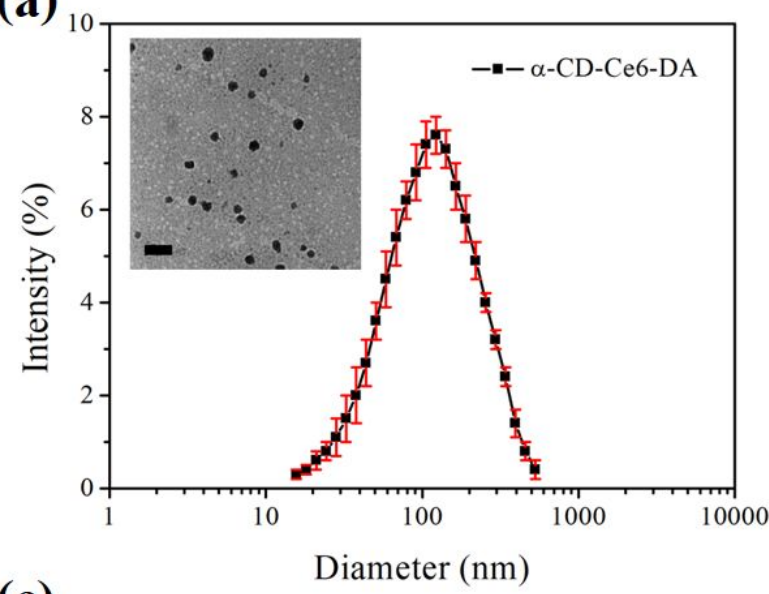

(c)

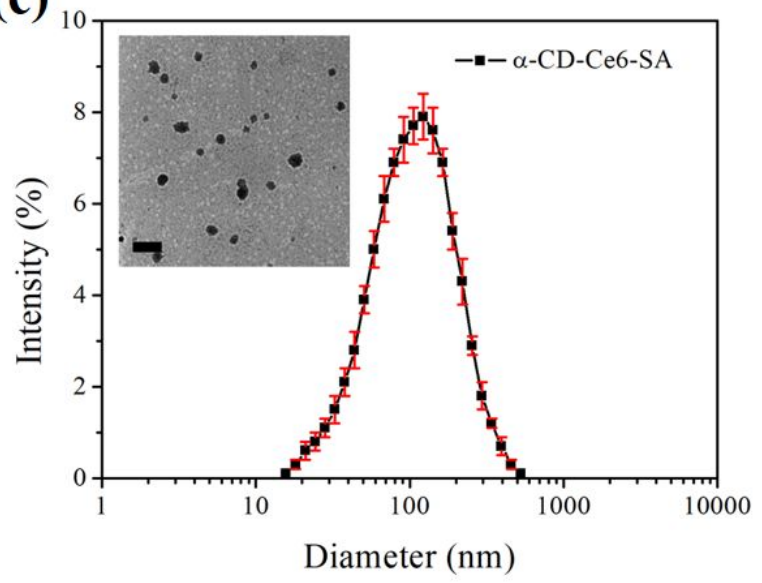

(b)

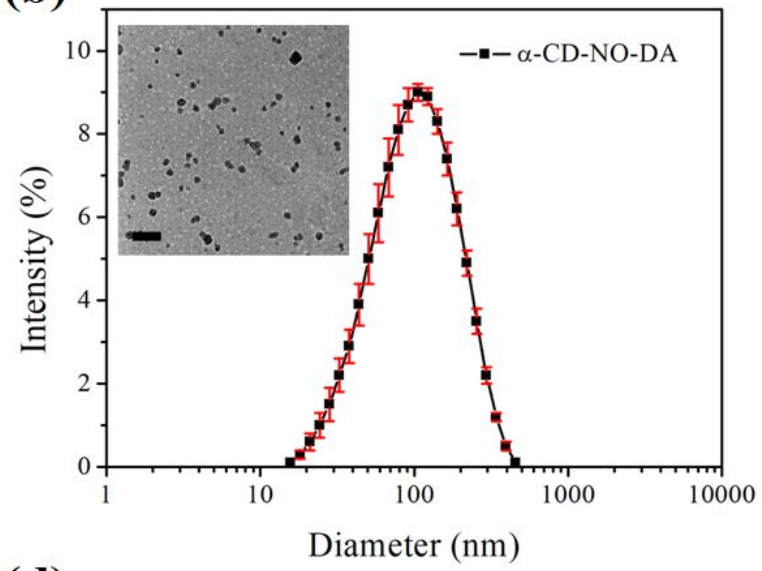

(d)

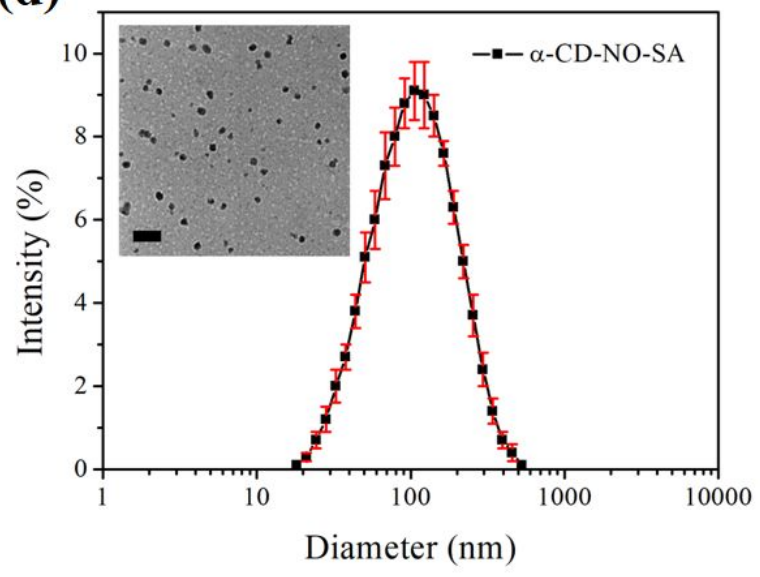

Figure S3. Hydrodynamic diameter $(\mathrm{Dh})$ and TEM images of (a) $\alpha$-CD-Ce6-DA, (b) $\alpha$-CDNO-DA, (c) $\alpha$-CD-Ce6-SA and (d) $\alpha$-CD-NO-SA. Scale bar: $400 \mathrm{~nm}$. 


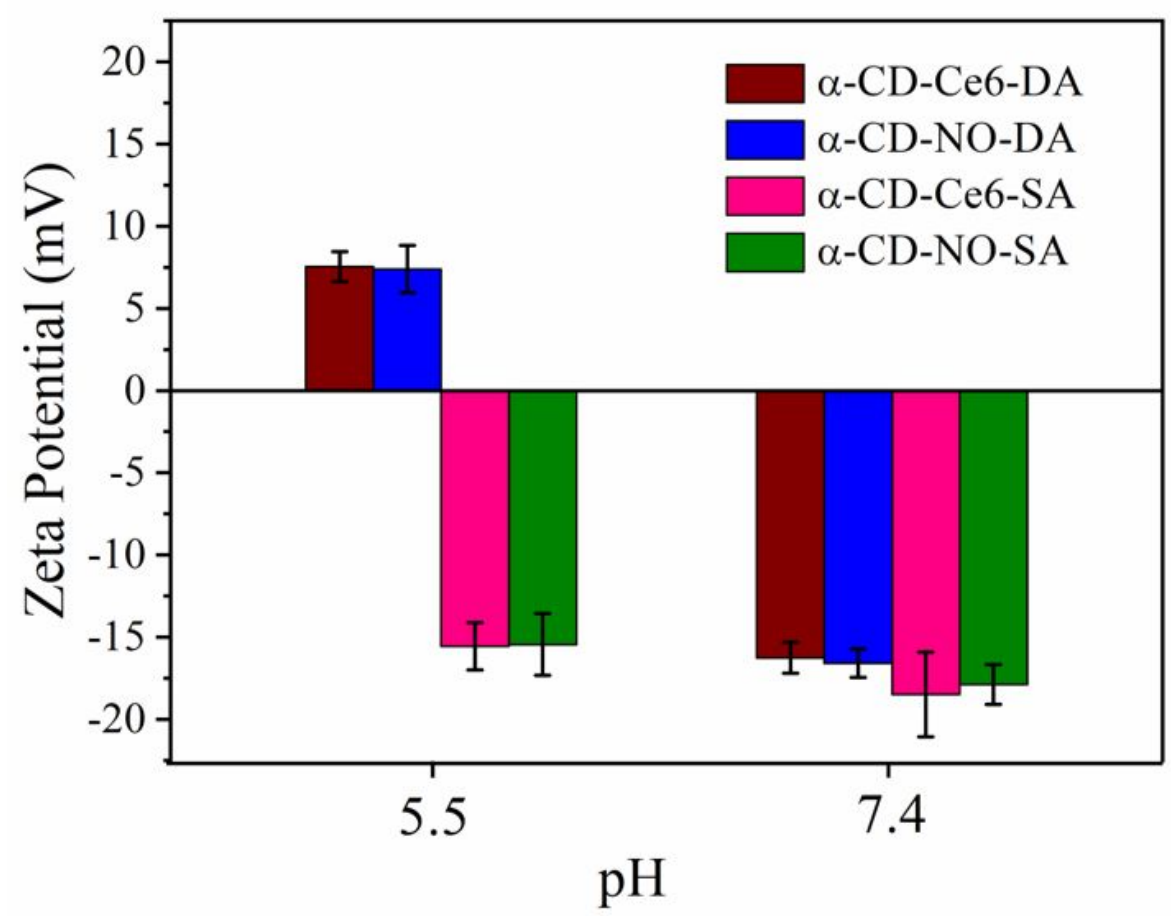

Figure S4. Zeta potential of $\alpha$-CD-Ce6-DA, $\alpha$-CD-NO-DA, $\alpha$-CD-Ce6-SA and $\alpha$-CD-NO-SA at $\mathrm{pH} 5.5$ and $\mathrm{pH} 7.4$, respectively. 
(a)

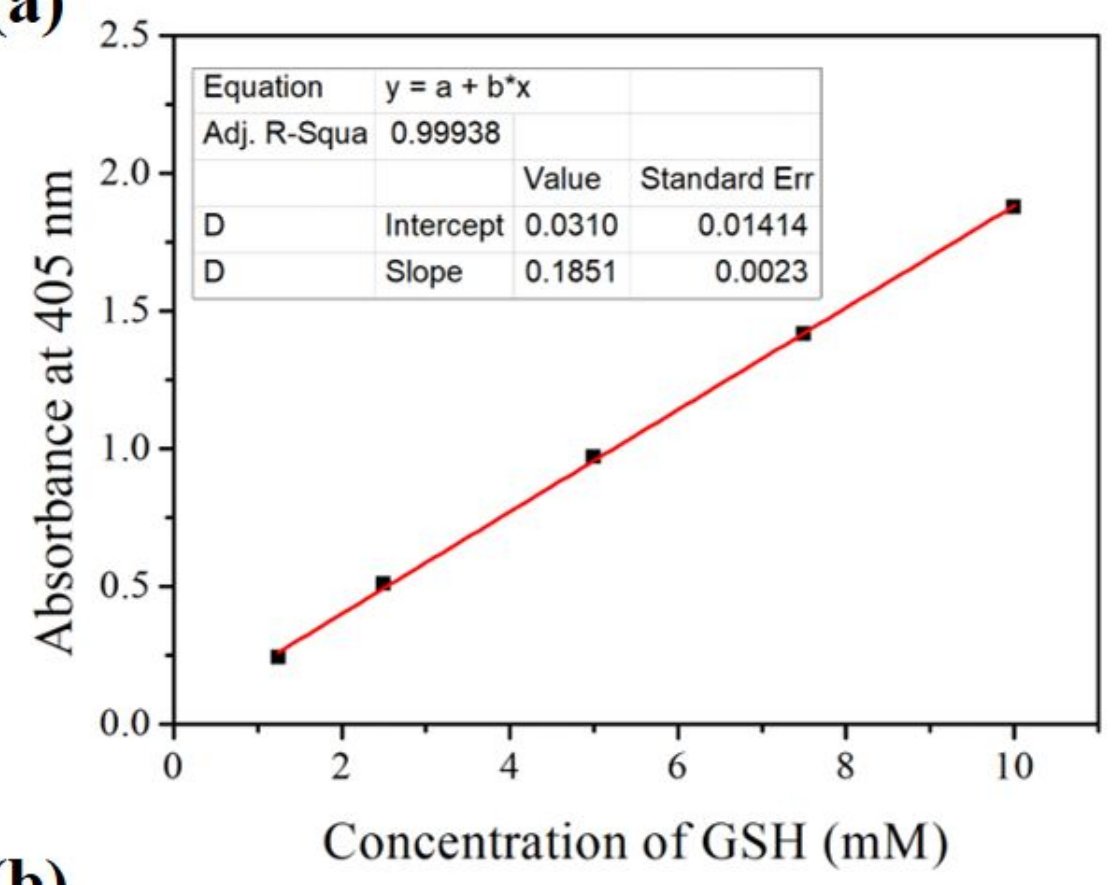

(b)

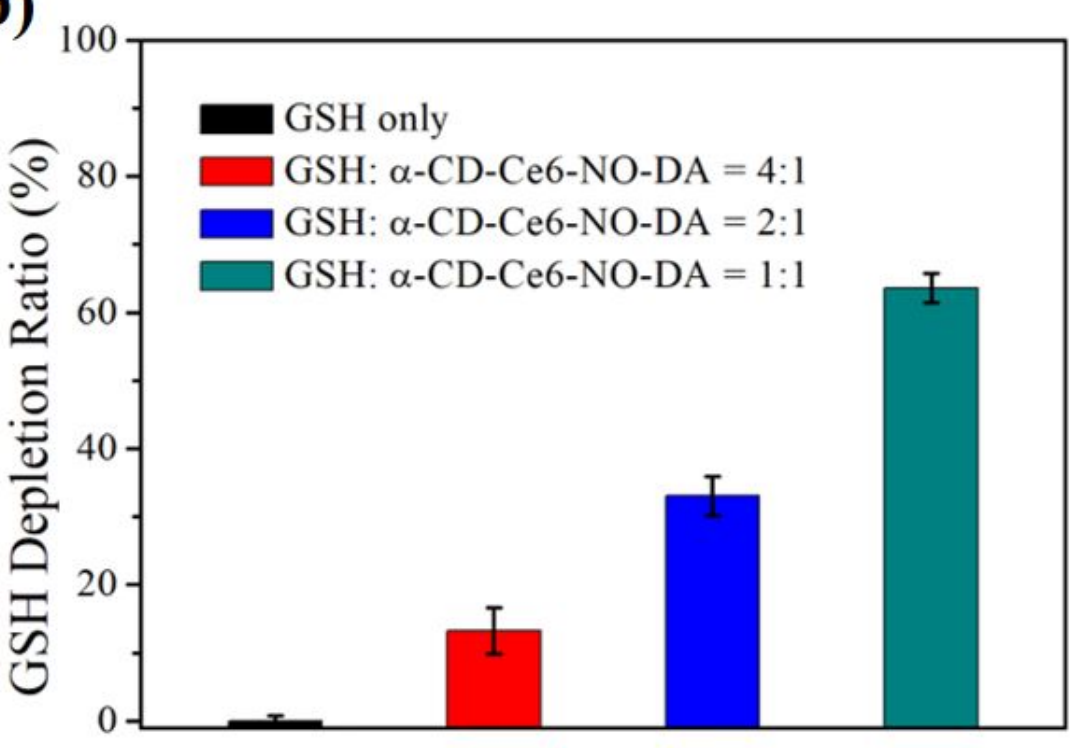

Figure S5. (a) Standard curve of GSH test kit absorbance at $405 \mathrm{~nm}$ versus the concentration of GSH measured by UV-Vis spectrum; (b) The corresponding GSH depletion ratio with different treatments. 


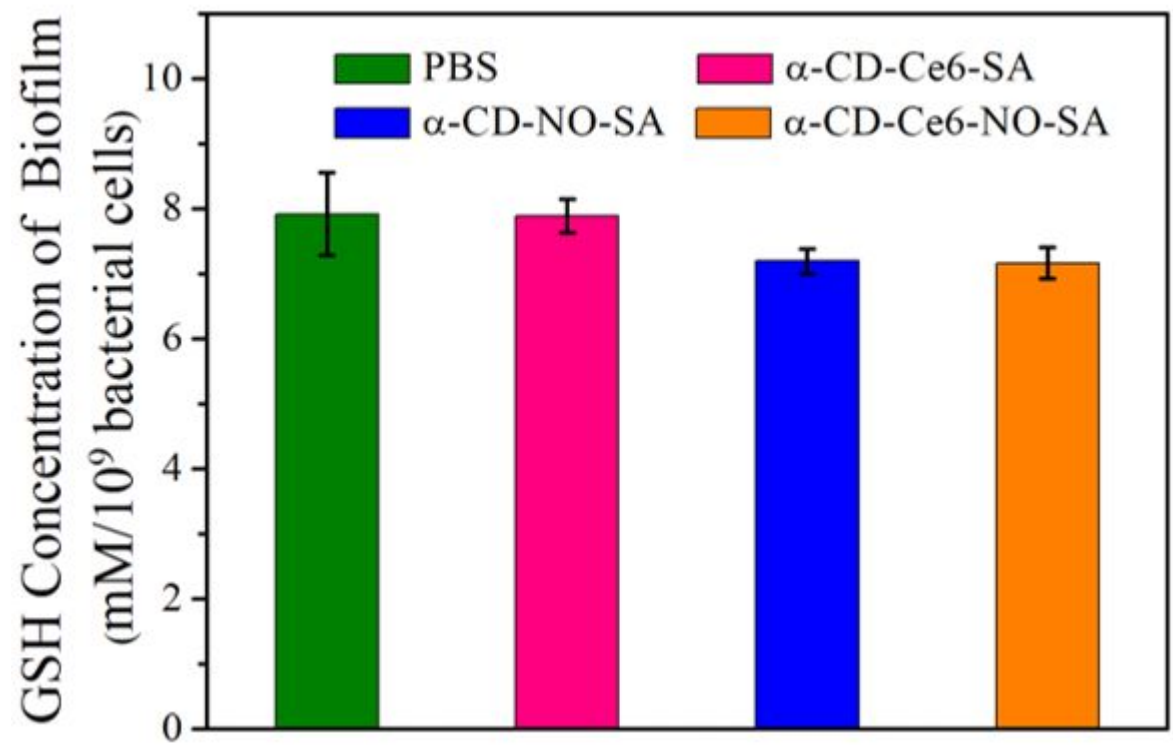

Figure S6. GSH concentration of MRSA biofilm after incubation with PBS, $\alpha$-CD-Ce6-SA, $\alpha-$ CD-NO-SA and $\alpha$-CD-Ce6-NO-SA for one hour respectively (Ce6 $10 \mu \mathrm{g} \mathrm{mL} \mathrm{L}^{-1}$ and NO $20 \mu \mathrm{g}$ $\left.\mathrm{mL}^{-1}\right)$. 

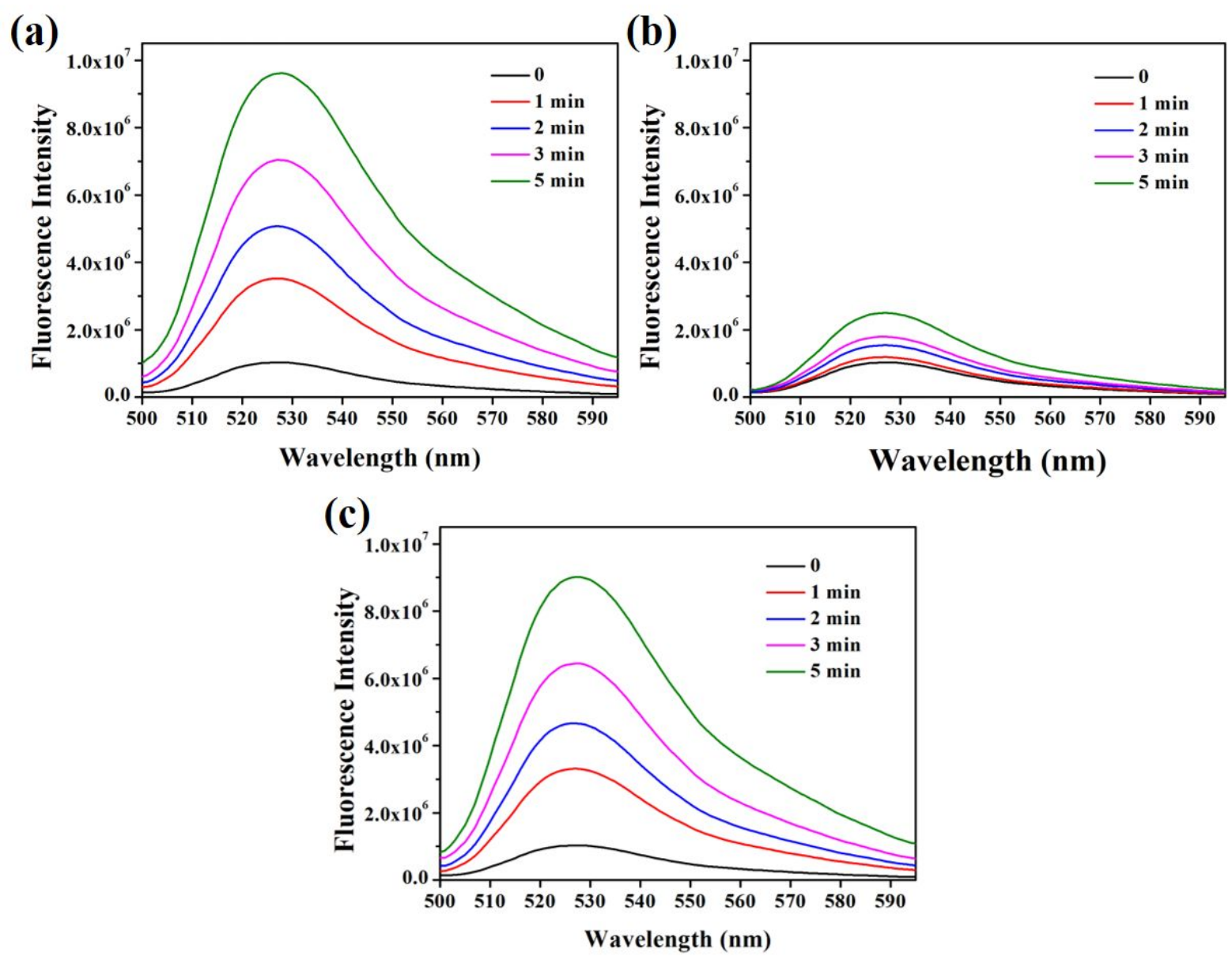

Figure S7. Plots of the absorbance change of DCF after different irradiation time. (a) $\alpha$-CDCe6-DA in PBS without GSH; (b) $\alpha$-CD-Ce6-DA in PBS with 8 mM GSH; (c) $\alpha$-CD-Ce6-NODA in PBS with $8 \mathrm{mM} \mathrm{GSH}\left(\mathrm{Ce} 620 \mu \mathrm{g} \mathrm{mL}^{-1}\right.$, NO $\left.40 \mu \mathrm{g} \mathrm{mL} L^{-1}\right)$. 


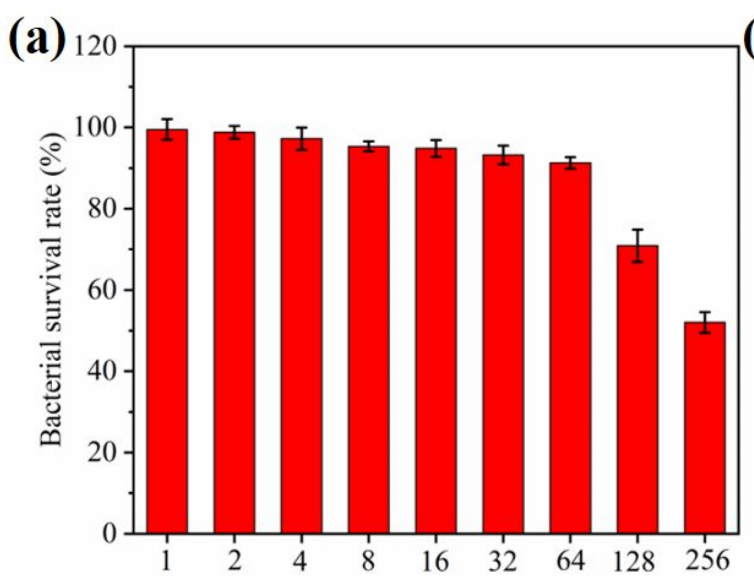

(c)

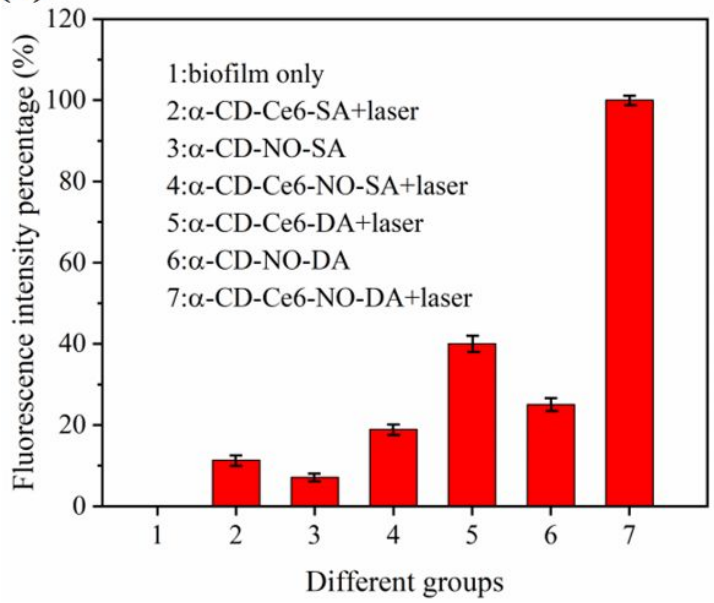

(b)

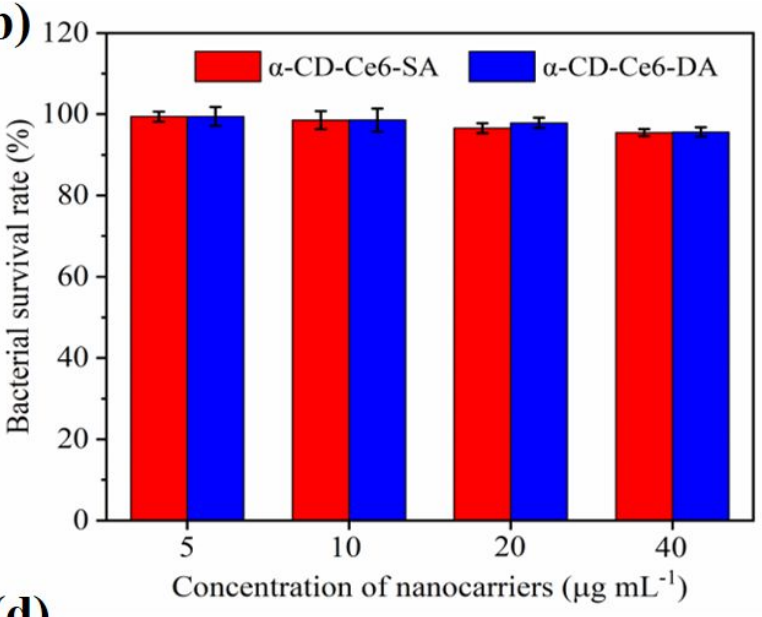

(d)

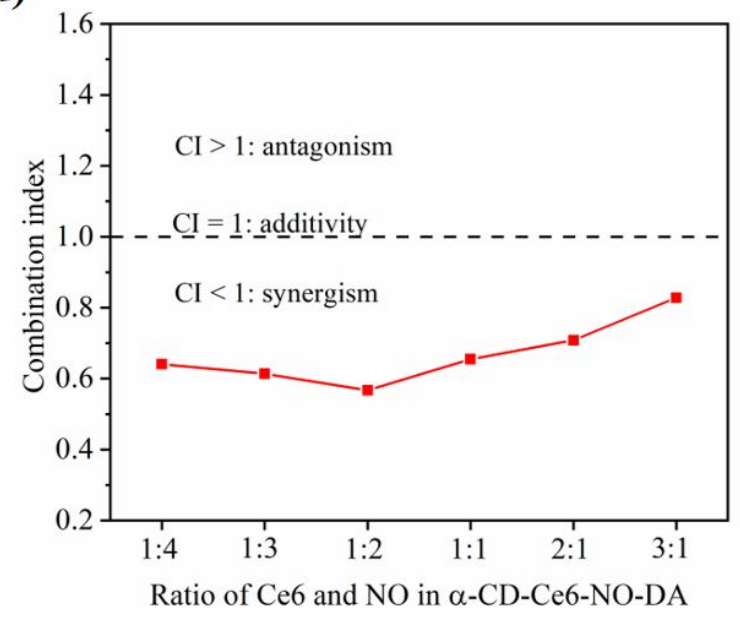

Figure S8. (a) Bacterial survival rate of biofilm after incubation with (KLAKLAK) $)_{2}$ peptide in various concentrations; (b) Bacterial survival rate of biofilm after incubation with $\alpha$-CDCe6-SA and $\alpha$-CD-Ce6-Da at different concentrations without laser irradiation; (c) The semiquantitative statistics of the fluorescence intensity percent of different groups stained with propidium iodide; (d) Combination index (CI) curves of $\mathrm{Ce} 6$ and NO in $\alpha$-CD-Ce6-NO-DA. 
(a)

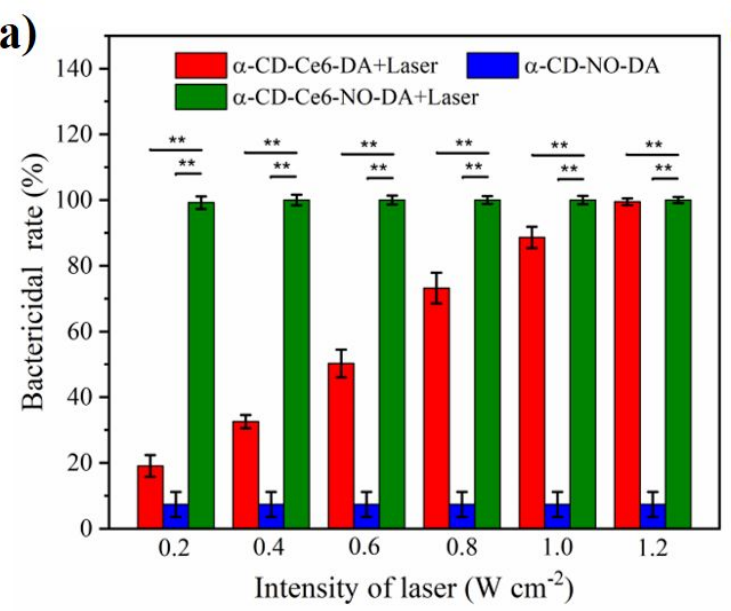

(b)

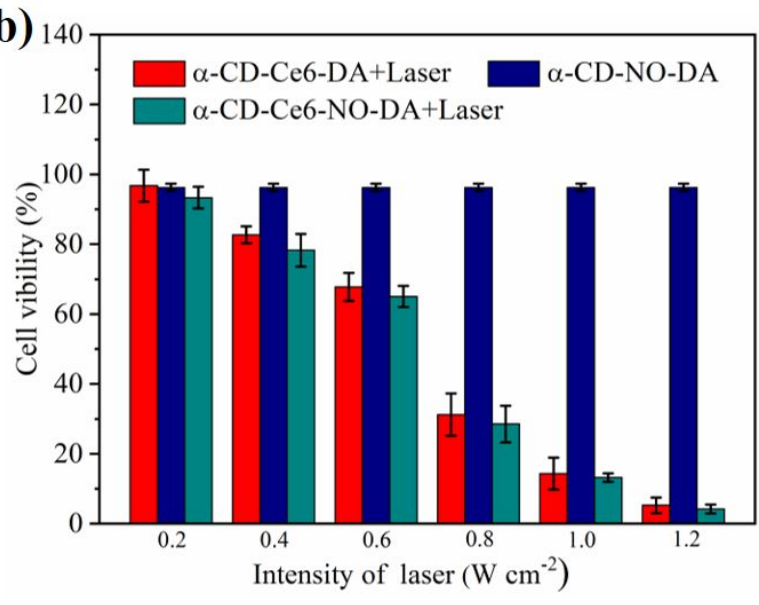

Figure S9. (a) The bactericidal rate of $\alpha$-CD-Ce6-DA (Ce6 $10 \mu \mathrm{g} \mathrm{mL}{ }^{-1}$ ), $\alpha$-CD-NO-DA (NO $20 \mu \mathrm{g} \mathrm{mL}^{-1}$ ), and $\alpha$-CD-Ce6-NO-DA (Ce6 $10 \mu \mathrm{g} \mathrm{mL}^{-1}$, NO $20 \mu \mathrm{g} \mathrm{mL}^{-1}$ ) under different laser intensity irradiation (1 min) compared with PBS-treated control group; (b) Cytotoxicity of NIH 3T3 fibroblast cells after incubation with $\alpha$-CD-Ce6-DA (Ce6 $10 \mu \mathrm{g} \mathrm{mL} \mathrm{L}^{-1}$ ), $\alpha$-CD-NO-DA (NO $20 \mu \mathrm{g} \mathrm{mL}^{-1}$ ), and $\alpha$-CD-Ce6-NO-DA (Ce6 $10 \mu \mathrm{g} \mathrm{mL}^{-1}$, NO $20 \mu \mathrm{g} \mathrm{mL}^{-1}$ ) under different laser intensity irradiation (1 min). Statistical analysis was performed using the student's two-tailed $\mathrm{t}$ test $(* * \mathrm{p}<0.01)$ 


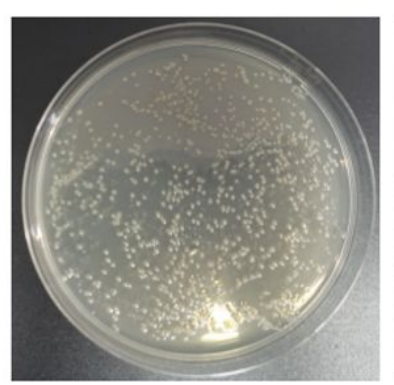

Biofilm only

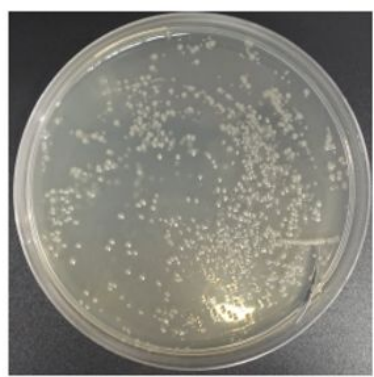

$\alpha$-CD-Ce6-DA

+laser

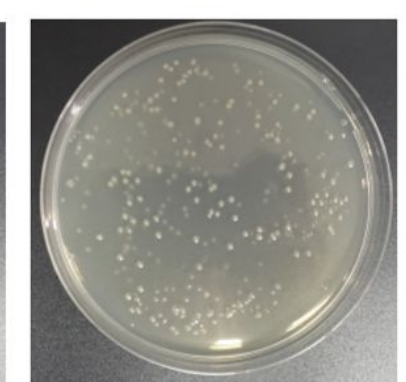

a-CD-NO-DA

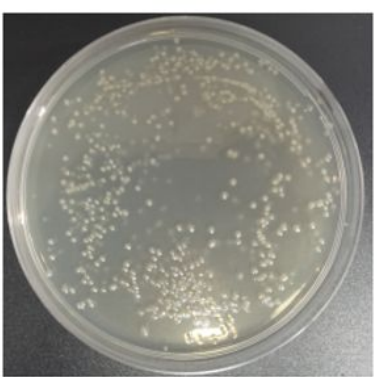

a-CD-NO-DA

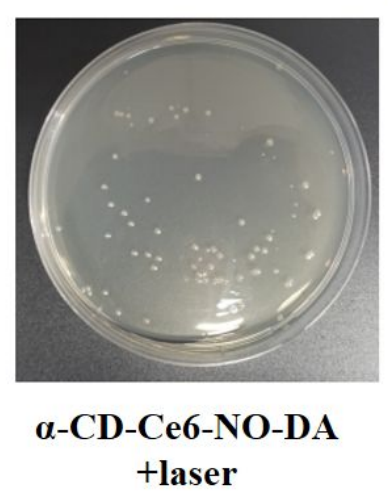

$\alpha$-CD-Ce6-NO-DA

+laser

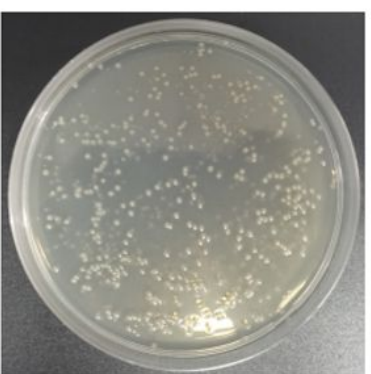

a-CD-Ce6-NO-SA

+laser

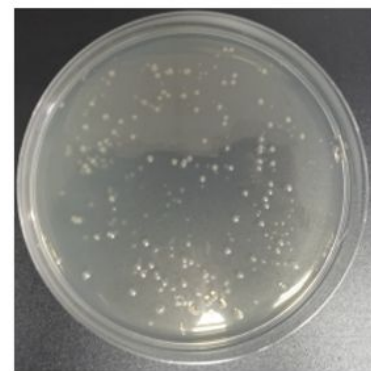

a-CD-Ce6-DA

+laser

Figure S10. Photos of bacterial colony forming units obtained from biofilm infected tissue of mice treated with different groups.

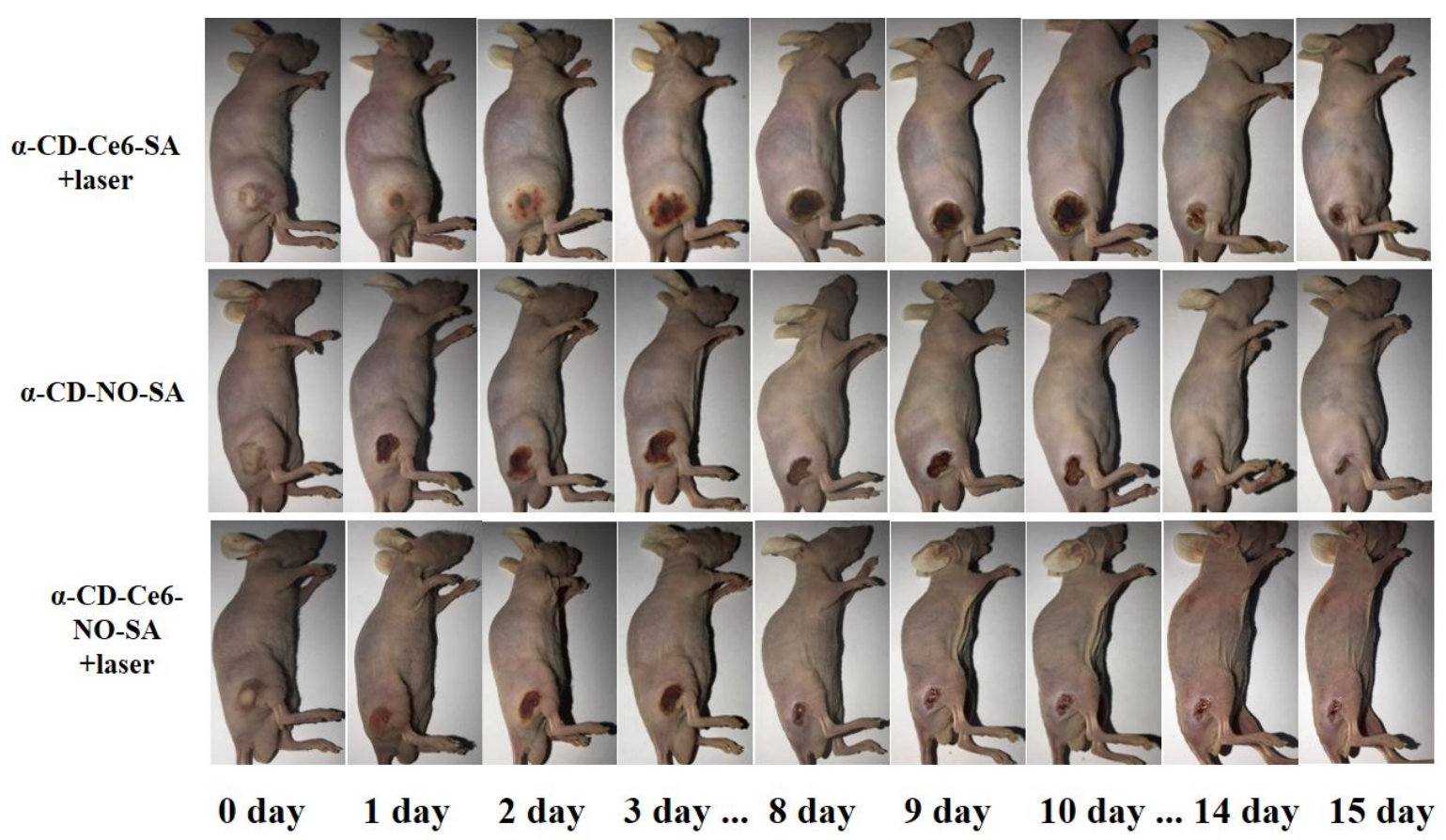

Figure S11. Representative photographs of the MRSA $\left(10^{8} \mathrm{cfu} \mathrm{mL}^{-1}\right)$ infected mice within 15 
days postinjection in three different treatment groups ( $\alpha$-CD-Ce6-SA with laser, $\alpha$-CD-NO-SA and $\alpha$-CD-Ce6-NO-SA with laser).

(a)

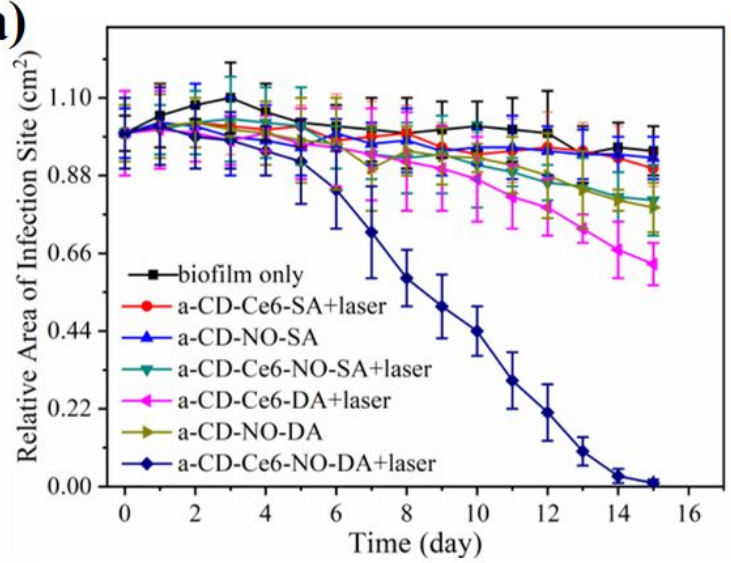

(c)

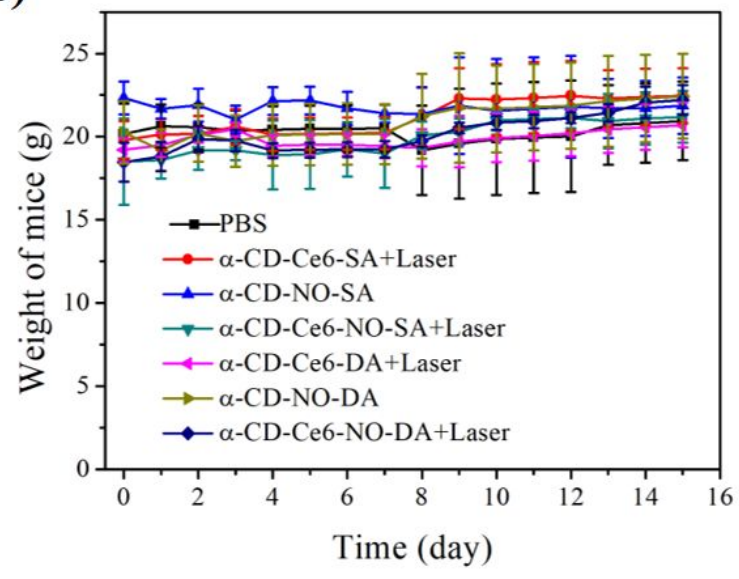

(b)

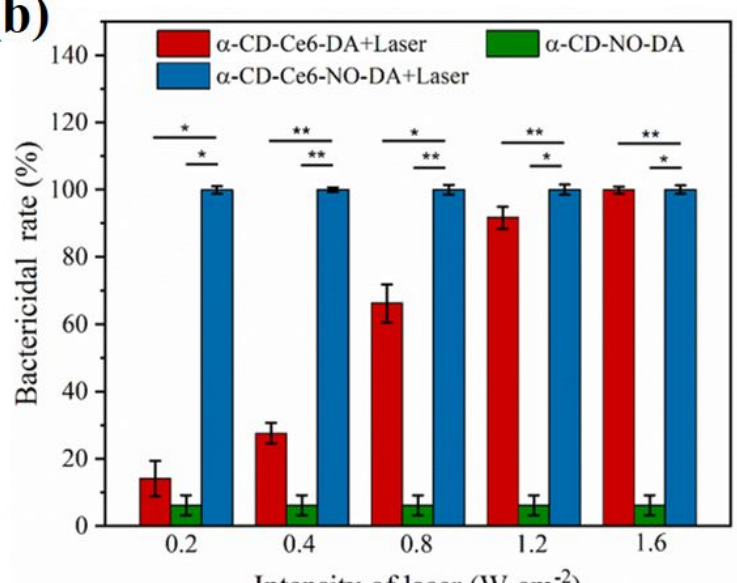

Intensity of laser $\left(\mathrm{W} \mathrm{cm}^{-2}\right)$

Figure S12. (a) The areas of biofilm infection of the mice after different treatments with same Ce6 concentration $\left(10 \mu \mathrm{g} \mathrm{mL}^{-1}\right)$ under laser irradiation $\left(0.2 \mathrm{~W} \mathrm{~cm}^{-2}, 1 \mathrm{~min}\right)$; (b) The bactericidal rate of $\alpha$-CD-Ce6-DA (Ce6 $10 \mu \mathrm{g} \mathrm{mL}^{-1}$ ), $\alpha$-CD-NO-DA (NO $20 \mu \mathrm{g} \mathrm{mL} \mathrm{L}^{-1}$ ), and $\alpha$-CD-Ce6NO-DA (Ce6 $10 \mu \mathrm{g} \mathrm{mL}^{-1}$, NO $20 \mu \mathrm{g} \mathrm{mL}^{-1}$ ) under different laser intensity irradiation (1 min) compared with PBS-treated control group; (c) Body weight curves of MRSA biofilm infected mice after different nanocarrier treatments with same Ce6 concentration $\left(10 \mu \mathrm{g} \mathrm{mL}{ }^{-1}\right)$ under laser irradiation $\left(0.2 \mathrm{~W} \mathrm{~cm}^{-2}, 1 \mathrm{~min}\right)$. 